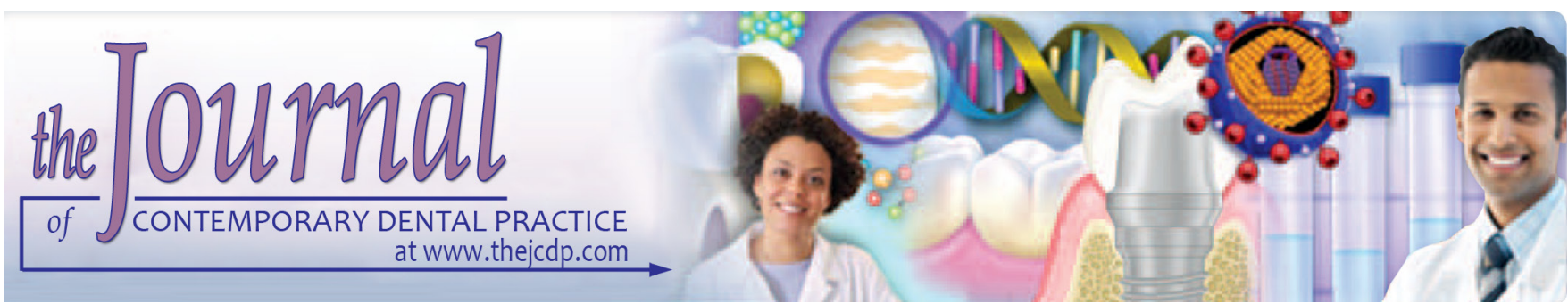

\title{
Comparison between Classic Twin-block and a Modified Clear Twin-block in Class II, Division 1 Malocclusions: A Randomized Clinical Trial
}

\author{
${ }^{1}$ Farzaneh Golfeshan, ${ }^{2}$ Mohammad K Soltani, ${ }^{3}$ Asieh Zohrei, ${ }^{4}$ Jalal Poorolajal
}

\begin{abstract}
Aim: The aim of this study was to compare dentoskeletal effects and patient's satisfaction with a modified twin-block (clear twinblock) and classic twin-block.

Materials and methods: A total of 62 patients with skeletal class II malocclusion contributing to mandibular retrognathism with a minimum of $4 \mathrm{~mm}$ overjet, the FMA angle between 20 to 25 degree and being in stage 2 to 3 of cervical vertebral maturation participated in this study. Subjects were randomized in 1:1 ratio to classic and clear twin-block. Lateral cephalograms were taken at two stages-Pre- and post-treatment (when the overjet reduced to 1 to $0 \mathrm{~mm}$ ). All the measurements were done with Dolphin software version 10.5. Four months after the start of the treatment the patients were asked to fill the questioners regarding their compliance from the appliances.
\end{abstract}

Results: Both classic and clear twin -block groups showed mandibular advancement without statistically significant difference between them. However, SNB angle increased slightly more in clear group than the classic one." Headgear effect" is not statistically noticeable in both groups. However, SNA angle decreased slightly more in Classic group. Increased in lower incisors proclination was happening in both groups, but in a clear group, this increase was significantly less. Overbite reduction could be seen in both groups with significantly more reduction in the classic group.

${ }^{1}$ Department of Orthodontics, Orthodontic Research Center, Shiraz University of Medical Science, Shiraz, Islamic Republic of Iran

${ }^{2}$ Department of Orthodontics, Hamadan University of Medical Sciences, Hamadan, Islamic Republic of Iran

${ }^{3}$ Department of Epidemiology and Biostatistics, Hamadan University of Medical Sciences, Hamadan, Islamic Republic of Iran

${ }^{4}$ Department of Pediatric Dentistry, School of Dentistry, Shiraz University of Medical Science, Shiraz, Islamic Republic of Iran

Corresponding Author: Asieh Zohrei, Department of Pediatric Dentistry, School of Dentistry, Shiraz University of Medical Science, Shiraz, Islamic Republic of Iran, Phone: +09177325259, e-mail: a.zohrei84@gmail.com
Conclusion: Increase in lower incisors proclination was less in clear group than the classic one. Overbite reduction was more in the classic group than the classic one.

Clinical significance: Clear twin-block is more beneficial in skeletal class II patients with proclined lower incisors and vertical growth pattern.

Keywords: Appliance, Functional orthodontic, Twin-block

Trial registration: Iranian research clinical trial, Agreement NO.2014040817180N1

How to cite this article: Golfeshan F, Soltani MK, Zohrei A, Poorolajal J. Comparison between Classic Twin-block and a Modified Clear Twin-block in Class II, Division 1 Malocclusions: A Randomized Clinical Trial. J Contemp Dent Pract 2018;19(12):1456-1463.

Source of support: Nil

Conflict of interest: Trial registration: Iranian research clinical trial, agreement No.2014040817180N1

\section{INTRODUCTION}

Functional jaw orthopedics is a specific type of treatment in growing patients with class II malocclusion associated with mandibular retrognathism. ${ }^{1}$ Various designs of appliances have been used for this purpose. ${ }^{2,3}$ These appliances contribute to class II correction with a combination of dentoalveolar and skeletal effects with the preference of the later. However the mode of action for each appliance depends on its design. ${ }^{4-6}$

The twin-block appliance, originally developed by Clark, is a widely used functional appliance. ${ }^{7-8}$ The appliance consists of maxillary and mandibular acrylic plates with bite blocks, which interlock at a $70^{\circ}$ angle on closure while posturing the mandible forward. Increasing mandibular body length, inhibition of maxillary growth, retroincliantion of maxillary incisors and proclination of mandibular incisors were reported with this appliance in literature. ${ }^{9}$ 
Significant proclination of lower incisors had been consistently reported as a major side effect of Twin-block appliances. ${ }^{10}$ This complication, generally acknowledged for functional appliances, is attributed to a protrusive effect on the lower incisors exerted by the lingual appliance components while the mandible attempts to rebound to normal resting posture. ${ }^{11}$ Various design and modification of twin-block appliances have been used to decrease this side effect. ${ }^{2,5,12}$

Treatment effects of removable orthodontic appliances, irrespective of the particular individual therapeutic intervention and mode of action largely depend on the patient cooperation. ${ }^{13}$ One of the most important factors on patients' cooperation is the appearance of the appliance that may be unpleasant in social interactions. ${ }^{14}$

Given two items in consideration, lower incisors proclination with a twin-block appliance which is not desired and improvement of patients' acceptance of the appliance; we designed a modification of Twin-block appliances using clear polycarbonate sheets without any wire component. We named this modification "Clear Twin block".

The present study was designed to compare the treatment effects of the conventional Twin-block with the clear twin-block appliance, in the class II division 1 malocclusion. Patients' compliance was also assessed with the help of a questionnaire.

\section{MATERIALS AND METHODS}

Ethics committee approval was granted before the study began (Agreement No.2014040817180N1 IRCT). To detect a meaningful reduction of overjet with the $95 \%$ confidence interval and power of $80 \%$, a sample size of 30 patients per group wasnecessary. Briefly, the patients had to havea class II division 1 incisal relationship associated with mandibular retrognathia and a minimum overjet of $4 \mathrm{~mm}$ and the Florida Medical Association (FMA) angle between 20 to $25^{\circ}$. All the subjects were in stage 2 to 3 of cervical vertebral maturation. Subjects with any craniofacial anomalies, history of previous orthodontic therapy and trauma to jaws were excluded from the study. Patients were randomized in a 1:1 ratio to either classic or clear twin-block group. Randomization was accomplished with quadric block randomization method with allocation concealed in opaque, sealed envelopes.

The working bites for both groups were taken with the incisors in an edge-to-edge relationship and 3 to 4 $\mathrm{mm}$ bite opening between the central incisors. In Clear Twin-block group, bite registration was done while the Clear sheets were put on the upper and lower arches of the patients.

The classic twin-block appliance consisted of two removable upper and lower acrylic plates. The upper plates consisted of Adams clasp on first permanent molars and premolars or primary first molars and labial bow on anterior teeth. In the lower plate, the appliance consisted of Adams clasps on first premolars or first deciduous molars and labial bow on anterior teeth. All the components were formed with 0.028-inch stainless steel wire. Upper and lower acrylic blocks had inclined planes at $70^{\circ}$ to the occlusal plane.

In order to construct the clear twin-block, all the undercuts and semi erupted teeth were blocked out using molten wax. Upper and lower models were put individually on the vacuum machine using 1.5 $\mathrm{mm}$ clear thermoplastic sheet to form the base of the appliance. The adapted sheets were trimmed using a carborundum disc and the edges were smoothened. Working bite registration was done in the mouth with clear sheets, accounting for the thickness of the sheets for the vertical opening. The models with trimmed base clear plate were mounted in the hinge type articulator with construction bite and the inclined ramps with self-cured acryl have been formed on the plates similar to traditional one. The clear Twin-block appliance was shown in Figure 1.

In both treatment groups, if further advancement is required, increments of self-cured acryl were added to the inclined ramps. The appliances were fabricated in the same laboratory. The patients were instructed to wear the appliance full time except for eating and brushing. Treatment was discontinued when an overjet and overbite reduced to 1 to $2 \mathrm{~mm}$.

Overjet reduction and other dentoskeletal and soft tissue effects were evaluated and compared in both groups analyzing cephalometric values before (T1) and after treatment (T2). All the cephalometric tracing and measurements were done with Dolphin software version 10.5. To assess measuring error, $20 \%$ of the pretreatment cephalometric radiographs were traced with another examiner. ICC for all the values was between 0.8 and 1 .

Patients' satisfaction from the appliance were evaluated with the questionnaires which were given to them at 4 months after the start of treatment. The questionnaires had 12 questions. Each question had four scales (strong agree $=4$, agree $=3$, somewhat agree $=2$, disagree $=1$ ). The values of question 1 to 12 were added. Sergel ${ }^{15}$ used this questionnaire for the first time to evaluate patients' satisfaction from orthodontic treatment. The questions could be seen in Table 1.

The primary outcome evaluated in this study was the comparison of lower incisors proclination after treatment in both groups. The secondary outcomes were the comparison of other dentoskeletal and soft tissue changes and patients' acceptance of the appliance in both groups. 


\section{Statistical Analysis}

Statistical Package for the Social Sciences (SPSS) version 20 was used for data analysis. Homogeneity of pretreatment values between the two groups was assessed using independent $t$-test. The paired $t$-test was used to evaluate dentoskeletal effects of each appliance. The independent t-test was used to compare treatment results and find differences between the two groups. Mann-Whitney U test was used for questionnaire data analysis. (The p-value $\leq 0.05$ was considered statistically significant)

\section{RESULTS}

Graph 1 shows the process of subjects' enrollment in this study.

Sixty-two patients were randomized in a 1:1 ratio to either classic or clear twin-block group. ${ }^{4}$ patients were lost to follow-up ( 1 in classic twin block group and 3 others in clear twin block group). Demographic data and the overjet at the start of treatment were shown in Table 2.

Treatment duration in Classic group was $10.18 \pm$ 1.17 months, and in the clear group was $9.05 \pm 1.42$ months. There was a statistically significant difference in treatment duration between two groups ( $p=0 / 002)$. Comparison of the pre- and post-treatment mean values of cephalometric measurements in each group was shown in Table 3. Comparison of cephalometric changes (T2-T1) between the two groups was shown in Table 4.

\section{Skeletal Measurements}

In general, there was not any significant difference between the two groups regarding pretreatment skeletal measurements (Table 3).

The mandible became prognathic in both groups after the treatment (Table 3).
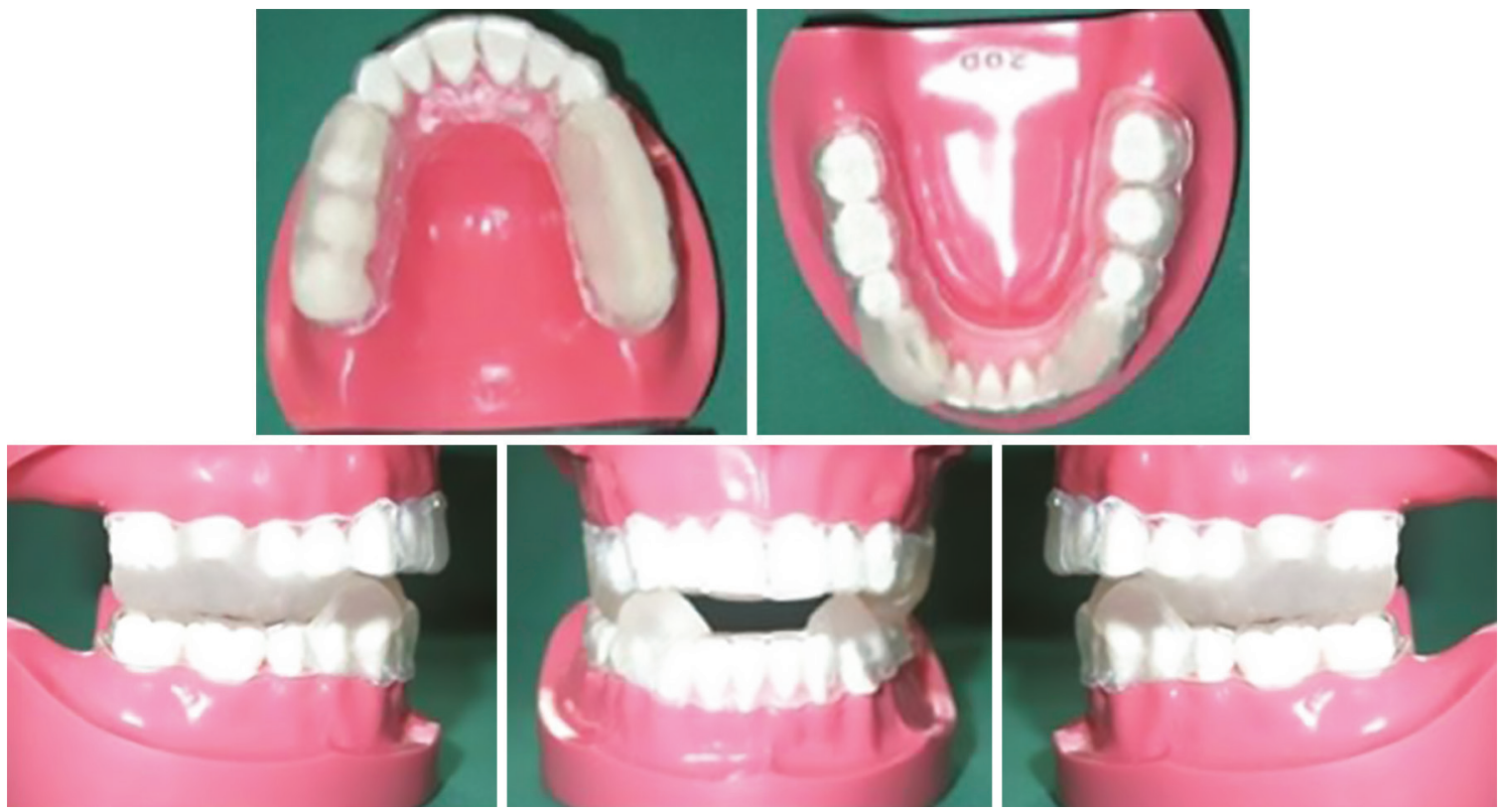

Fig. 1: Clear Twin-block appliance

Table 1: The questionnaire given to patients

\begin{tabular}{ll}
\hline \multicolumn{1}{c}{ Questions } & 1 \\
\hline My appliance is comfortable & 2 \\
My appliance does not interfere with chewing & 3 \\
My appliance does not interfere with breathing & 4 \\
My appliance does not interfere with sleeping & 5 \\
My appliance does not interfere with Speaking & 6 \\
My appliance does not cause vomiting & 7 \\
My appliance does not interfere with school activity & 8 \\
My appliance does not cause any negative influence & \\
on my friendship & 9 \\
My appliance does not cause any negative influence & \\
on my family relationship & 10 \\
My appliance does not cause pain & 11 \\
My appliance appearance does not annoy me & 12 \\
If needed I suggest this appliance to my friends
\end{tabular}

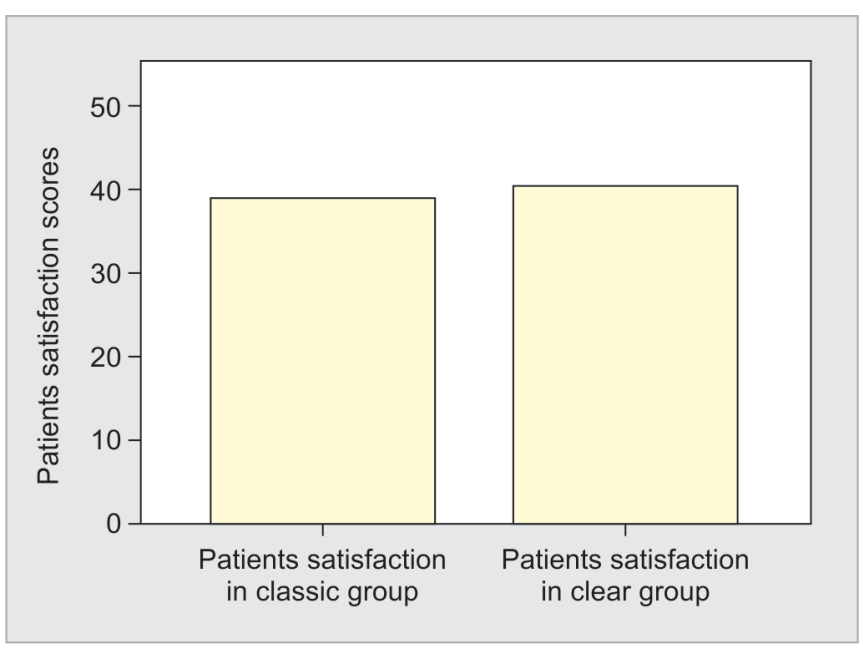

Graph 1: Comparison of patients satisfaction from classic and clean twin-block 
Anterior-posterior face height increased significantly after the treatment in both groups (Table 3).

There was not any significant difference in skeletal values between the two groups after the treatment (Table 4).

Table 2: Demographic data and overjet at the stat of the treatment

\begin{tabular}{llllll}
\hline & Number & \multicolumn{3}{c}{ sex } & \multicolumn{2}{l}{ Age } & \\
\cline { 2 - 5 } Group & & $M$ & $F$ & Mean $+S D$ & Overjet \\
\hline Classic & 30 & 17 & 13 & $9.9 \pm 0 / 8$ & $7.49 \pm 1.51$ \\
Clear & 28 & 14 & 14 & $9.8 \pm 1.06$ & $7.29 \pm 1.96$ \\
\hline
\end{tabular}

\section{Dental Measures}

In general, there was not any significant difference between the two groups regarding pretreatment cephalometric dental values.

There was a significant change in anterior-posterior and vertical position of mandibular first molars in two groups (Table 3). Lower incisor proclination, overjet, and overbite reduction were significant in two groups after the treatment.

Table 3: Comparison of the Pre and Post treatment mean values in each group

\begin{tabular}{|c|c|c|c|c|c|c|c|}
\hline \multirow{3}{*}{ Variable } & \multicolumn{2}{|c|}{ Classic Twin-block } & \multirow{3}{*}{$p$-value } & \multicolumn{2}{|c|}{ Clear Twin-Block } & \multirow[b]{3}{*}{$p$-value } & \multirow[b]{3}{*}{ Homogeneity** } \\
\hline & Pre-Treatment & Post-Treatment & & Pre-Treatment & Post-Treatment & & \\
\hline & Mean $\pm S D$ & Mean $\pm S D$ & & Mean $\pm S D$ & Mean $\pm S D$ & & \\
\hline \multicolumn{8}{|c|}{ Maxillary and mandibular skeletal } \\
\hline SNA & $82.93 \pm 4.43$ & $81.77 \pm 2.96$ & 0.061 & $81.3 \pm 4.13$ & $81.82 \pm 4.28$ & 0.478 & 0.155 \\
\hline SNB & $75.99 \pm 3.97$ & $77.27 \pm 2.85$ & $0.049^{*}$ & $74.88 \pm 3.43$ & $77.17 \pm 3.4$ & $0.004^{*}$ & 0.250 \\
\hline Na prep to A point & $0.17 \pm 3.81$ & $-1.86 \pm 3.18$ & $0.011^{*}$ & $-1.03 \pm 3.08$ & $-2.25 \pm 3.07$ & $0.022^{*}$ & 0.194 \\
\hline Na prep to pog & $-9.87 \pm 4.38$ & $-8.07 \pm 5.1$ & $0.005^{*}$ & $-11.11 \pm 6.11$ & $-9.3 \pm 5.70$ & $0.020^{\star}$ & 0.991 \\
\hline Co- ANS & $80.89 \pm 7.18$ & $83.34 \pm 6.96$ & 0.052 & $80.07 \pm 5.75$ & $82.77 \pm 7.40$ & 0.075 & 0.950 \\
\hline GO-GN & $73.07 \pm 7.25$ & $76.62 \pm 6.5$ & $0.000^{*}$ & $71.09 \pm 6.56$ & $74.33 \pm 6.84$ & $0.000^{*}$ & 0.282 \\
\hline GO-POG & $65.52 \pm 6.25$ & $68.33 \pm 5.95$ & $0.000^{*}$ & $64.48 \pm 4.94$ & $67.18 \pm 5.14$ & $0.000^{*}$ & 0.488 \\
\hline SN/GO-GN & $29.53 \pm 4.24$ & $30.84 \pm 5.25$ & 0.058 & $31.07 \pm 3.43$ & $32.24 \pm 3.87$ & 0.063 & 0.136 \\
\hline \multicolumn{8}{|l|}{ Maxilla to mandible } \\
\hline ANB & $6.93 \pm 2.26$ & $4.47 \pm 1.9$ & $0.001^{*}$ & $6.62 \pm 2.19$ & $4.67 \pm 2.07$ & $0.000^{*}$ & 0.256 \\
\hline Wits & $5.31 \pm 2.85$ & $2.02 \pm 2.91$ & $0.000^{*}$ & $5.51 \pm 2.26$ & $2.27 \pm 2.40$ & $0.000^{*}$ & 0.773 \\
\hline Harvold & $16.52 \pm 4.04$ & $19.01 \pm 4.23$ & $0.002^{*}$ & $14.86 \pm 4.42$ & $17.15 \pm 4.91$ & $0.002^{*}$ & 0.141 \\
\hline \multicolumn{8}{|l|}{ Maxillary dental } \\
\hline U1/SN & $108.93 \pm 5.98$ & $108.08 \pm 6.5$ & 0.075 & $107.70 \pm 5.98$ & $107.15 \pm 5.80$ & 0.072 & 0.435 \\
\hline U1/PP & $112.96 \pm 9.00$ & $112.1 \pm 8.81$ & 0.351 & $113.28 \pm 7.23$ & $111.24 \pm 7.04$ & 0.082 & 0.882 \\
\hline U1/NA & $25.49 \pm 4.65$ & $25.05 \pm 4.21$ & 0.116 & $24.95 \pm 4.43$ & $23.91 \pm 4.55$ & 0.103 & 0.651 \\
\hline U1-NA(mm) & $4.60 \pm 3.2$ & $4.21 \pm 2.54$ & 0.492 & $4.55 \pm 2.83$ & $4.10 \pm 2.11$ & 0.324 & 0.970 \\
\hline U6/PP & $19.59 \pm 2.47$ & $19.72 \pm 3.09$ & 0.789 & $20.61 \pm 2.29$ & $20.50 \pm 2.78$ & 0.827 & 0.107 \\
\hline $\begin{array}{l}\text { Horz PIn/T } \\
\phi \text { Pt Perp-U6 Mesial }\end{array}$ & $33.133 \pm 5.14$ & $32.92 \pm 5.03$ & 0.619 & $35.43 \pm 3.11$ & $36.42 \pm 4.29$ & 0.056 & 0.06 \\
\hline \multicolumn{8}{|l|}{ Mandibular dental } \\
\hline IMPA & $94.13 \pm 4.12$ & $100.19 \pm 5.88$ & $0.000^{*}$ & $94.82 \pm 4.55$ & $98.76 \pm 4.64$ & $0.000^{*}$ & 0.546 \\
\hline L1-MP(mm) & $39.05 \pm 2.14$ & $39 \pm 2.81$ & 0.134 & $37.76 \pm 2.98$ & $38.23 \pm 3.77$ & 0.312 & 0.060 \\
\hline L1/NB & $25.56 \pm 3.31$ & $30.84 \pm 3.21$ & $0.000^{*}$ & $26.67 \pm 4.47$ & $30.12 \pm 4.08$ & $0.000^{*}$ & 0.280 \\
\hline L1-NB(mm) & $4.74 \pm 1.41$ & $6.71 \pm 1.67$ & $0.000^{*}$ & $4.54 \pm 1.21$ & $6.43 \pm 1.84$ & $0.000^{*}$ & 0.594 \\
\hline L6-MP & $26.96 \pm 2.98$ & $29.02 \pm 2.81$ & $0.000^{*}$ & $27.16 \pm 2.84$ & $28.65 \pm 3.27$ & $0.002^{*}$ & 0.340 \\
\hline $\begin{array}{l}\text { Horz PIn/T } \phi \text { Pt } \\
\text { Perp-L6 Mesial }\end{array}$ & $33.133 \pm 5.14$ & $32.92 \pm 5.03$ & 0.619 & $32.34 \pm 4.28$ & $35.82 \pm 4.22$ & $0.000^{*}$ & 0.282 \\
\hline \multicolumn{8}{|l|}{ Interdental } \\
\hline Interincisal angle & $125.62 \pm 6.39$ & $124.01 \pm 6.72$ & $0.035^{*}$ & $122.97 \pm 9.70$ & $121.60 \pm 9.32$ & 0.188 & 0.224 \\
\hline Overbite & $3.73 \pm 1.72$ & $1.60 \pm 1.53$ & $0.000^{*}$ & $3.54 \pm 1.40$ & $2.36 \pm 1.21$ & $0.000^{*}$ & 0.660 \\
\hline Overjet & $7.49 \pm 1.51$ & $2.32 \pm 0.64$ & $0.000^{*}$ & $7.29 \pm 1.96$ & $2.25 \pm 0.87$ & $0.000^{*}$ & 0.669 \\
\hline \multicolumn{8}{|l|}{ Vertical } \\
\hline Posterior Face Height & $69.80 \pm 6.40$ & $73.80 \pm 7.65$ & $0.000^{*}$ & $68.63 \pm 4.96$ & $72.02 \pm 6.05$ & $0.000^{*}$ & 0.442 \\
\hline Anterior Face Height & $110.55 \pm 7.7$ & $116.50 \pm 7.99$ & $0.000^{*}$ & $108.19 \pm 8.30$ & $123.52 \pm 10.06$ & $0.001^{*}$ & 0.268 \\
\hline $\mathrm{PFH} / \mathrm{AFH}$ & $63.22 \pm 5.1$ & $63.32 \pm 4.86$ & 0.881 & $63.55 \pm 3.75$ & $64.22 \pm 4.93$ & 0.316 & 0.770 \\
\hline \multicolumn{8}{|l|}{ Soft tissue } \\
\hline Nasolabial angle & $105.39 \pm 10.58$ & $106.24 \pm 9.95$ & 0.128 & $109.33 \pm 10.74$ & $109.74 \pm 10.62$ & $0.001^{*}$ & 0.165 \\
\hline Lower lip-Eline & $-1.26 \pm 2.02$ & $-0.19 \pm 1.85$ & $0.000^{*}$ & $-1.29 \pm 1.99$ & $-0.51 \pm 2.16$ & $0.032^{*}$ & 0.948 \\
\hline Upper lip-Eline & $-0.98 \pm 2.48$ & $-2.94 \pm 2.04$ & $0.000^{*}$ & $0.15 \pm 3.16$ & $-1.60 \pm 2.73$ & $0.001^{*}$ & 0.135 \\
\hline
\end{tabular}

*:Significance level $<0.05$

**:Homogeneity of Pretreatment measures

$\phi: T$ point, It is the most superior point of the anterior wall of sella turcica 
Table 4: Comparison of cephalometric changes (T2-T1) between two groups

\begin{tabular}{|c|c|c|c|}
\hline & Classic Twin-block & Clear Twin-block & \\
\hline Variable & T2-T1 Mean & T2-T1 Mean & Intergroup comparisons \\
\hline \multicolumn{4}{|c|}{ Maxillary and mandibular skeletal } \\
\hline SNA & -1.16 & 0.51 & 0.076 \\
\hline SNB & 1.27 & 2.29 & 0.286 \\
\hline Na prep to A point & -2.03 & -1.22 & 0.900 \\
\hline Na prep to pog & 1.80 & 1.81 & 0.991 \\
\hline Co- ANS & 2.65 & 2.05 & 0.731 \\
\hline GO-GN & 3.54 & 3.23 & 0.731 \\
\hline GO-POG & 2.81 & 2.70 & 0.884 \\
\hline SN/GO-GN & 1.31 & 1.17 & 0.870 \\
\hline \multicolumn{4}{|l|}{ Maxilla to mandible } \\
\hline ANB & -2.46 & -1.95 & 0.053 \\
\hline wits & -3.20 & -3.23 & 0.932 \\
\hline Harvold & 2.48 & 2.28 & 0.842 \\
\hline \multicolumn{4}{|l|}{ Maxillary dental } \\
\hline U1/SN & -0.85 & -0.54 & 0.581 \\
\hline U1/PP & -0.86 & -2.03 & 0.410 \\
\hline U1/NA & -0.44 & -1.03 & 0.368 \\
\hline U1-NA(mm) & -0.39 & 0.36 & 0.950 \\
\hline U6/PP & 0.13 & -1.14 & 0.740 \\
\hline $\begin{array}{l}\text { Horz PIn/T } \phi \text { Pt Perp - U6 } \\
\text { Mesial }\end{array}$ & 0.2 & 0.98 & 0.061 \\
\hline \multicolumn{4}{|l|}{ Mandibular dental } \\
\hline IMPA & 6.06 & 3.94 & $0.032^{*}$ \\
\hline L1/MP & 0.59 & 0.47 & 0.830 \\
\hline L1/NB & 5.28 & 3.35 & $0.034^{*}$ \\
\hline L1-NB(mm) & 1.96 & 1.88 & 0.810 \\
\hline L6/MP & 2.33 & 1.48 & 0.089 \\
\hline $\begin{array}{l}\text { Horz PIn/T } \phi \text { Pt } \\
\text { Perp - L6 Mesial }\end{array}$ & 2.9 & 3.41 & 0.331 \\
\hline \multicolumn{4}{|l|}{ Interdental } \\
\hline Interincisal angle & -1.60 & -1.36 & 0.846 \\
\hline overbite & -2.13 & -1.18 & $0.048^{*}$ \\
\hline overjet & -5.14 & -5.03 & 0.814 \\
\hline \multicolumn{4}{|l|}{ Vertical } \\
\hline Posterior Face Height & 3.99 & 3.39 & 0.547 \\
\hline Anterior Face Height & 5.97 & 4.32 & 0.543 \\
\hline $\mathrm{PFH} / \mathrm{AFH}$ & 0.09 & 0.66 & 0.615 \\
\hline \multicolumn{4}{|l|}{ Soft tissue } \\
\hline \multirow[t]{2}{*}{ Nasolabial angle } & 0.85 & & \\
\hline & 0.40 & 0.737 & \\
\hline Lower lip-Eline & 1.06 & 0.78 & 0.498 \\
\hline Upper lip-Eline & -1.96 & -1.75 & 0.761 \\
\hline
\end{tabular}

*:Significance level $<0.05$

$\phi$ :T point: It is the most superior point of the anterior wall of sella turcica

In comparison between two groups, proclination of lower incisors was less in clear Twin-block group than Classic group (Table 4).

\section{Soft Tissue Measures}

Protrusion of upper lip and retrusion of lower lip were seen after treatment in both groups, but there was not any significant difference between the two groups (Table 3).

\section{Patients' Satisfaction}

According to questionnaires data, there were not any significant differences between two groups regarding acceptance of the appliances ( $p$-value $=0.513$ ). The mean 
scores of the two groups were reported in the form of a Bar chart (Chart 2).

\section{DISCUSSION}

The result of the present study showed that mandibular anterior-posterior position was changed significantly after treatment in both groups. The mandible became prognathic in both groups. Cephalometric values showed that mandibular position became slightly more advanced in a clear group than classic one, but there is no statistically significant difference between groups. In studies using different twin block modifications, conflicting reports were mentioned regarding changes in mandibular position. MC Culloch, ${ }^{16}$ Mills, ${ }^{17}$ Tummer and Gulton ${ }^{18}$ reported significant advancement of mandible following twin block therapy, while some other studies did not find significant changes in mandibular position. ${ }^{19,20}$ Singh $^{21}$ in 2017 used a modification of twin block with thermoplastic sheets (like our study) and named this appliance "Essix Twin-block". He compared this design with classic twin block in 14 patients. Increase in SNB angle was significantly more in Essix group than the classic one. The result of his study is different from ours. the mentioned study was done with less sample size and was not in a randomized clinical trial setting. It is suggested that more study with randomized controlled trial (RCT) designed and with more sample need to resolve these conflicts.

Maxillary position relative to the cranial base was not significantly changed after treatment in both groups. when the mandible became advanced with the aid of functional appliances, a reciprocal force acts distally on the maxilla. This force called" Headgear effect" can be an inhibitor of forwarding growth of the maxilla. ${ }^{22,23}$ Some studies found significant headgear effect with twin block therapy, ${ }^{24,25}$ while others did not mention this effect. ${ }^{26,27}$ As we said previously there are no significant changes in maxillary position in both groups, however becoming more precise in Cephalometric values student nurses' association (SNA) angle was decreased slightly more in the classic group than the clear one.

It could be suggested that in patients with class II jaws relationship, and need to advance the mandible it is slightly more effective to use clear design and in patients who need more Headgear effect, it is better to use the classic design of twin block. For more precise conclusion regarding skeletal effects of these two appliances more clinical trial studies with larger sample size would be required.

The primary objective of designing new modification of twin block appliance was decreasing some of its adverse effects. Increased lower incisor proclination was one of these adverse effects. In this study a significant increase in lower incisor proclination was happening in both groups while comparing two groups, lower incisor proclination was significantly less in clear group. To decrease mandibular incisor proclination, different modification of twin block appliance has been introduced in the literature. Adding acrylic cap in the lower incisors region is one of these modifications. Sidlauskas ${ }^{28}$ in his study mentioned that this capping is useful in the inhibition of lower incisor proclination, while Vander Pla12 reported that adding acrylic cap had no benefits in decreasing lower incisor proclination.

Kattan $^{29}$ in his study using a modification of twin block with thermoplastic sheets covering all teeth in lower arch and classic designed in upper arch reported a 2-degree increase in lower incisor proclination which was not significant. In Singh study using Essix Twin-block, mandibular incisors became procline in both groups after treatment without any significant differences between them. ${ }^{12}$ The result of his study was different from ours. The lower strength of thermoplastic sheets used in the later study which was $1 \mathrm{~mm}$ thickness could be the result of this difference that cannot inhibit lower incisor proclination.

The result of the present study supports the idea that coverage of lower incisors in clear group can decrease lower incisor ploclination, so as the clinical significance of the result of this study in case of class II with lower incisor proclination it is better to use clear twin block than the classic one.

Upper incisors proclination were not changed significantly after treatment in both groups. Decreased upper incisors proclination was reported in Toth and Namara study following twin-block therapy. ${ }^{22}$ this can be happening due to contact of the wire to the labial surface of teeth during muscle contraction, or during sleep. Singh in his study reported no significant changed in upper incisor inclination during treatment with essix and conventional twin block. more studies with the same protocol may be needed to identify this effect. ${ }^{21}$

The mesial and vertical eruption of lower first molars had been reported in some studies after treatment with twin- block. ${ }^{30,31}$ This can be happening due to selective grinding of the acrylic coverage of lower molars to promote guidance of eruption in these teeth.in this study mesial movement and the vertical eruption of lower first molars were seen in both groups with no statistically significant differences between them. However, the vertical eruption of lower molars was slightly more in the classic group than the clear one. This can be due to full coverage of anterior and posterior teeth during treatment in a clear group which intruded these teeth.

Overbite reduction was significant in both groups after the treatment with more reduction in Classic 
group. This can be happening in two ways; (1) more lower incisors proclination in classic group; (2) more vertical eruption of lower first molar and consequently more autorotation of the mandible in classic group. This can be suggesting that classic twin-block could be more beneficial in horizontal class II patients, while it is better to use clear Twin-block in class II patients with vertical growth pattern.

Patients satisfaction from the appliances were not significantly different in the two groups. In analyzing each question individually, the only difference between the two groups was in speech item. The clear group has a lesser problem with speech, which could be due to absent of acrylic coverage in palate in this appliance. In Singh's study patients had less speech problem with Essix Twin-block too. ${ }^{21}$

The major limitation of our study is the absence of long-term follow-up to evaluate the stability of treatment outcomes.

\section{CONCLUSION}

- Both classic and clear twin-block appliance can advance the mandible but headgear effect is not significant in both groups.

- Lower incisor proclination was seen in both groups but lesser in clear group than classic ones.

- Overbite reduction was more in a classic group than a clear one.

- Patients' satisfaction was not statistically different in the two groups, but the speech problem was less in clear group.

\section{REFERENCES}

1. Franchi L, Pavoni C, Faltin K Jr, McNamara JA Jr, Cozza P. Response to Long-term skeletal and dental effects and treatment timing for functional appliances in Class II malocclusion. Angle Orthod. 2013;83(5):933.

2. Flores-Mir C, Major PW. Cephalometric facial soft tissue changes with the twin block appliance in Class II division 1 malocclusion patients: A systematic review. Angle Orthod. 2006;76(5):876-881.

3. Baccetti T, Franchi L, Toth LR, McNamara JA Jr. Treatment timing for Twin-block therapy. Am J Orthod Dentofacial Orthop. 2000;118(2):159-170.

4. Yaqoob O, Dibiase AT, Fleming PS, Cobourne MT. Use of the Clark Twin Block functional appliance with and without an upper labial bow: a randomized controlled trial. Angle Orthod. 2012;82(2):363-369.

5. Trenouth MJ, Desmond S. A randomized clinical trial of two alternative designs of Twin-block appliance. J Orthod. 2012;39(1):17-24.

6. Al-Anezi SA . Class II malocclusion treatment using combined Twin Block and fixed orthodontic appliances-A case report. Saudi Dent J. 2011;23(1):43-51.
7. Hanoun A, Al-Jewair T, Tabbaa S, Allaymouni M, Preston C. A comparison of the treatment effects of the Forsus Fatigue Resistance Device and the Twin Block appliance in patients with class II malocclusions. Clin Cosmet Investig Dent. 2014; 6: 57-63.

8. Baysal A, Uysal T. Soft tissue effects of Twin Block and Herbst appliances in patients with Class II division 1 mandibular retrognathy. European Journal of Orthodontics.2011; doi:10.1093/ejo/cjq187

9. Toth LR, McNamara JA Jr. Treatment effects produced by the twin-block appliance and the FR-2 appliance of Fränkel compared with an untreated Class II sample. Am J Orthod Dentofacial Orthop. 1999 ;116(6):597-609.

10. Ehsani S, Nebbe B, Normando D, Lagravere MO, Flores-Mir C. Short-term treatment effects produced by the Twin-block appliance: a systematic review and meta-analysis. Eur J Orthod. 2015;37(2):170-176.

11. Macey-Dare LV, Nixon F. Functional appliances: mode of action and clinical use. SADJ. 1999 ;54(10):474-479.

12. van der Plas MC, Janssen KI, Pandis N, Livas C. Twin Block appliance with acrylic capping does not have a significant inhibitory effect on lower incisor proclination. Angle Orthod. 2017;87(4):513-518.

13. Skidmore KJ, Brook KJ, Thomson WM, Harding WJ. Factors influencing treatment time in orthodontic patients. Am J Orthod Dentofacial Orthop. 2006 ;129(2):230.

14. Doll GM1, Zentner A, Klages U, Sergl HG. Relationship between patient discomfort, appliance acceptance and compliance in orthodontic therapy. J Orofac Orthop. 2000;61(6):398-413.

15. Sergl H, Klages U, Pempera J.On the prediction of dentistevaluated pateint compliance in orthodontics. Eur J Orthod.1992;(14):463-468.

16. Mills CM, McCulloch KJ. Posttreatment changes after successful correction of Class II malocclusions with the Twin-block appliance. Am J Orthod Dentofacial Orthop 2000;118:2433.

17. Mills CM, McCulloch KJ. Treatment effects of the twin block appliance: a cephalometric study. Am J Orthod Dentofacial Orthop. 1998 ;114(1):15-24.

18. Tümer N, Gültan S. Comparison of the effects of monobloc andTwin-block appliances on the skeletal and dentoalveolar structures. Am J Orthod Dentofacial Orthop .1999;116:460-468.

19. Jakobsson S-O, Paulin G. The influence of activator on skeletal growth in Angle Class II:1 cases. A roentgenocephalometric study. Eur J Orthod .1990;12:174-184.

20. Chadwick SM, Aird JC, Taylor PJS, Bearn DR. Functionalregulator treatment of Class II Division 1 malocclusions. Eur J Orthod .2001;23:495-505.

21. Singh A, Chain S, Kulshrestha R, Gupta M, Passi D, Singh M. Comparison between conventional Twin block and a modified Essix twin block in adolescents with Class II malocclusion. International Journal of Dentistry Research. 2016;1(1):1-5.

22. Toth LR, McNamara JA Jr. Treatment effects produced by the twin-block appliance and the FR-2 appliance of Fränkel compared with an untreated Class II sample. Am J Orthod Dentofacial Orthop. 1999 ;116(6):597-609.

23. O'Brien K, Wright J, Conboy F, Sanjie Y, Mandall N, Chadwick $\mathrm{S}$,et al. Effectiveness of early orthodontic treatment with the Twin-block appliance: a multicenter, randomized, controlled 
trial. Part 1: Dental and skeletal effects. Am J Orthod Dentofacial Orthop. $2003 ; 124(3): 234-243$.

24. Kerr WJ, TenHave TR, McNamara JA Jr. A comparison of skeletal and dental changesproduced by function regulators (FR-2 and FR-3). Eur J Orthod. 1989;11:235-242.

25. Pancherz H. Treatment of Class II malocclusions by jumping the bite with the Herbst appliance: a cephalometric investigation. Am J Orthod .1979;76:423-442.

26. Perillo L, Johnston LE Jr, Ferro A. Permanence of skeletal changes after function regulator (FR-2) treatment of patients with retrusive Class II malocclusions. Am J Orthod Dentofacial Orthop .1996;109:132-139.

27. Hamilton SD, Sinclair PM, Hamilton RH. A cephalometric, tomographic, and dental cast evaluation of Fränkel therapy. Am J Orthod Dentofacial Orthop .1987;92:427-436.
28. Sidlauskas A. The effects of the Twin-block appliance treatment on the skeletal and dentolaveolar changes in Class II Division 1 malocclusion. Medicina (Kaunas). 2005;41(5):392-400.

29. El-Kattan E, El-Yazeed M, Aya E. A New Design of Twin Block Appliance for Treatment of Mandibular Deficiency in Mixed Dentition Stage. Aust. J. Basic \& Appl. Sci.2012; 6(10): 701-707.

30. Dauravu LM, Vannala V, Arafath M, Singaraju GS, Cherukuri SA, Mathew A. The assessment of sagittal changes with twin block appliance in patients with decelerating growth phase. J Clin Diagn Res. 2014 ;8(12):81-84.

31. Schaefer AT, McNamara JA Jr, Franchi L, Baccetti T. A cephalometric comparison of treatment with the Twin-block and stainless steel crown Herbst appliances followed by fixed appliance therapy. Am J Orthod Dentofacial Orthop. 2004;126(1):7-15. 